Research Paper

\title{
Altered RECQL5 expression in urothelial bladder carcinoma increases cellular proliferation and makes RECQL5 helicase activity a novel target for chemotherapy
}

\author{
Karl Patterson ${ }^{1}$, Lovleen Arya ${ }^{1, *}$, Sarah Bottomley ${ }^{1}$, Susan Morgan², Angela Cox ${ }^{1}$, \\ James Catto ${ }^{2}$, Helen E. Bryant ${ }^{1}$ \\ ${ }^{1}$ Academic Unit of Molecular Oncology, Sheffield Institute for Nucleic Acids (SInFoNiA), Department of Oncology and \\ Metabolism, University of Sheffield, Sheffield S10 2RX, United Kingdom \\ ${ }^{2}$ Academic Unit of Urology, Sheffield Institute for Nucleic Acids (SInFoNiA), Department of Oncology and Metabolism, \\ University of Sheffield, Sheffield S10 2RX, United Kingdom \\ *Current address: DuPont Knowledge Center, E.I.DuPont India Pvt Ltd., ICICI Knowledge Park, Genome Valley, \\ Hyderabad-500078, Andhra Pradesh, India
}

Correspondence to: Helen E. Bryant, email: h.bryant@sheffield.ac.uk

Keywords: RECQL5, helicase, bladder cancer, targeted therapy

Received: September 08, $2015 \quad$ Accepted: September 19, $2016 \quad$ Published: October 15, 2016

\section{ABSTRACT}

\begin{abstract}
RECQ helicases are a family of enzymes with both over lapping and unique functions. Functional autosomal recessive loss of three members of the family BLM, WRN and RECQL4, results in hereditary human syndromes characterized by cancer predisposition and premature aging, but despite the finding that RECQL5 deficient mice are cancer prone, no such link has been made to human RECQL5. Here we demonstrate that human urothelial carcinoma of the bladder (UCC) has increased expression of RECQL5 compared to normal bladder tissue and that increasing RECQL5 expression can drive proliferation of normal bladder cells and is associated with poor prognosis. Further, by expressing a helicase dead RECQL5 and by depleting bladder cancer cells of RECQL5 we show that inhibition of RECQL5 activity has potential as a new target for treatment of UCC.
\end{abstract}

\section{INTRODUCTION}

Urothelial carcinoma of the bladder (UCC) is the fourth most common cancer in men and seventh most common in women, affecting more than 400,000 people world wide annually [1]. Around $1 / 3$ of cancers are high grade and have a poor prognosis when invading into the bladder wall. The median survival for muscle invasive cancers is around $50 \%$ and has not improved in recent years, since the introduction of platinum based therapies [2-4]. Currently there is no treatment able to increase survival after platinum failure, thus there is an urgent need to develop new and effective agents. Molecular changes such as altered gene expression, have potential as targets to increase therapeutic response to conventional chemotherapies or as standalone agents. There has been some success in identifying molecular targets for therapy in UCC [5-7], which have lead to several current clinical trials $[8,9]$, however to date none have progressed to standard care.

Genomic stability plays a key role in preventing tumourigenesis and instability is a key hallmark of cancer
[10]. Alterations in the pathways responsible for maintain genomic instability can influence tumour development and response to therapy, while the same pathways can be themselves targets for therapy [11-15]. The RECQ helicases are conserved throughout evolution and contribute to genome stability through roles in replication, base excision repair, double-strand break repair, transcription, telomere maintenance and mitochondrial function [16]. All family members share a homologous helicase and RecQ C-Terminal domain, which contains a zinc-binding motif, a helix-hairpin-helix winged-helix domain and a $\beta$-hairpin motif. There are 5 mammalian RECQ helicases, RECQL (RECQ1), BLM (RECQ2), WRN (RECQ3), RECQL4, and RECQL5, having some over lapping and some distinct functions. Functional autosomal recessive loss of BLM, WRN and RECQL4, results in hereditary human syndromes characterized by cancer predisposition and premature aging (Bloom's, Werner's, and Rothmund-Thomson's syndromes, respectively) [17]. Further a number of polymorphisms are identified for the RECQ helicases that can determine 
survivability and susceptibility to cancers [18-24] and recently we demonstrated that increased expression of RECQL5 can be associated to poor prognosis in breast cancer [25]. While no hereditary disease is associated with RECQL5, deficient mice display high levels of spontaneous double strand breaks, are susceptible to gross chromosomal rearrangements and are prone to develop lymphomas and various solid tumours [26, 27], suggesting RECQL5 could also play a role in preventing tumourigenesis. In support of this RECQL5 is reported to have roles in suppression or repair of endogenous DNA damage [28-30], and in overcoming/repairing damage induced by DNA crosslinks [31-34], thymidine [35], hydroxyurea [33], camptothecin $[34,36]$ and transcriptionreplication collisions [37-40]. RECQL5 has 3 isoforms $\alpha$, $\beta$ and $\gamma$. While all 3 isoforms contain the helicase domain only the $\beta$ isoform is nuclear [41] and it is this form which is generally considered as being involved in the cellular DNA damage response pathway. For the most part in this work specifically RECQL5 $\beta$ is considered while reference to RECQL5 infers no specific isoform is being implicated.

We demonstrate that UCC have increased expression of RECQL5 $\beta$ compared to normal bladder tissue and that increasing RECQL5 $\beta$ expression can drive proliferation of normal bladder cells. Further by using a helicase dead RECQL5 $\beta$ we show that inhibition of RECQL5 activity is a potential new target for treatment of UCC.

\section{RESULTS}

\section{Primary UCCs have significantly increased expression of RECQL5 helicase protein}

Expression of RECQL5 helicase protein was analysed in 98 sporadic primary human UCC samples and 52 normal bladder tissue (Supplementary Table S1) using an antibody specific to RECQL5 $\beta$ (Supplementary Figure S1). Tissues were scored for strength of nuclear staining (Figure 1A). There was a highly significant increase in nuclear staining of RECQL5 in the malignant samples (Figure 1B, Contingency Table Pearson Chisquare test $\mathrm{P}=3.7 \times 10 \mathrm{e}-17$ ), with $90 \%$ of the malignant bladder samples scoring positive for RECQL5 $\beta$ compared to normal bladder samples where $83 \%$ of samples were negative for any nuclear staining. Tumour Samples were then grouped by stage and grade and RECQL5 intensity compared (Supplementary Figure S2). No significant difference in degree of RECQL5 $\beta$ expression was seen between tumour samples of differing stage (Contingency Table Pearson Chi-square test $\mathrm{P}=0.953$ ), and suggestive evidence of expression with higher-grade metastatic disease was seen but only when samples were grouped by staining vs. non-staining (Contingency Table Pearson Chi-square test $\mathrm{P}=0.035$ ). A small number of tumour adjacent normal samples were also analysed (Figure 2), no significant difference was detected most likely due to sample size however a trend to more RECQL5 staining compared to normal can be argued. Interestingly a few malignant samples $(n=3)$ and no normal samples displayed additional cytoplasmic staining for RECQL5 $\beta$, however numbers are too low to determine significance (data not shown).

Consistent with this western blotting revealed that three UCC cell lines, EJ, RT112 and RT4, have significantly higher levels of RECQL5 $\beta$ protein expression when compared to an immortalised normal bladder cell line, NHU hTERT (Figure 1C\&1D - Student's t-test, p values $=2.1 \times 10^{-3}, 4.4 \times 10^{-2}$ and $4.1 \times 10^{-2}$ respectively).

The number of RECQL5 foci in cells has been shown to vary throughout the cell cycle and it's expression is moderately increased following replication stress [35]. However when comparing UCC and normal bladder cell lines there was no significant difference in the percentage of cells in each phase of the cell cycle (Supplementary Figure S3) suggesting that differences in expression are tumour specific rather than cell cycle related. To further examine this in patient samples, a number of UCC tumour sections were stained for Ki67 in parallel to RECQL5; high RECQL5 staining could be seen with or without Ki67 staining, confirming that RECQL5 expression in tumours is not due only to increased cellular proliferation (Supplementary Figure S4). Finally in support of the change being unrelated altered proliferation, previous studies where RECQL5 was knocked out using gene distruption in DT40 cells, pulse labeling with BrdU staining demonstrated that the fraction of cells in S-phase is unaltered [32].

\section{Aggressive UCC has significantly increased levels of RECQL 5 mRNA, which are associated with worse survival}

Expression of RECQL5 mRNA was analysed in 197 primary UCC samples and 20 normal tissue samples (Supplementary Table S2). There was a significant increase in RECQL5 mRNA levels in the bladder cancers compared to the normal bladder tissue (Figure 2A - Student's t.test $p<0.001)$. A similar but less significant $(p=0.03)$ result was found when using a probe that specifically recognises $R E C Q L 5 \beta$ (data not shown). When tumours were stratified by grade, RECQL5 expression seemed highest in those of high grade but that were not yet invasive (Figure $2 \mathrm{~B}-$ Student's t.test $\mathrm{p}=0.04$ ). This is consistent with survival analysis whereby high RECQL5 mRNA was associated with reduced progression free survival (Figure $2 \mathrm{C}-\mathrm{log}$ rank test $\mathrm{p}=0.028$ ).

\section{Depletion of RECQL5 specifically reduces proliferation of $\mathrm{UCC}$ cells}

Cancer specific overexpression of a protein represents a potential site of therapeutic intervention. 

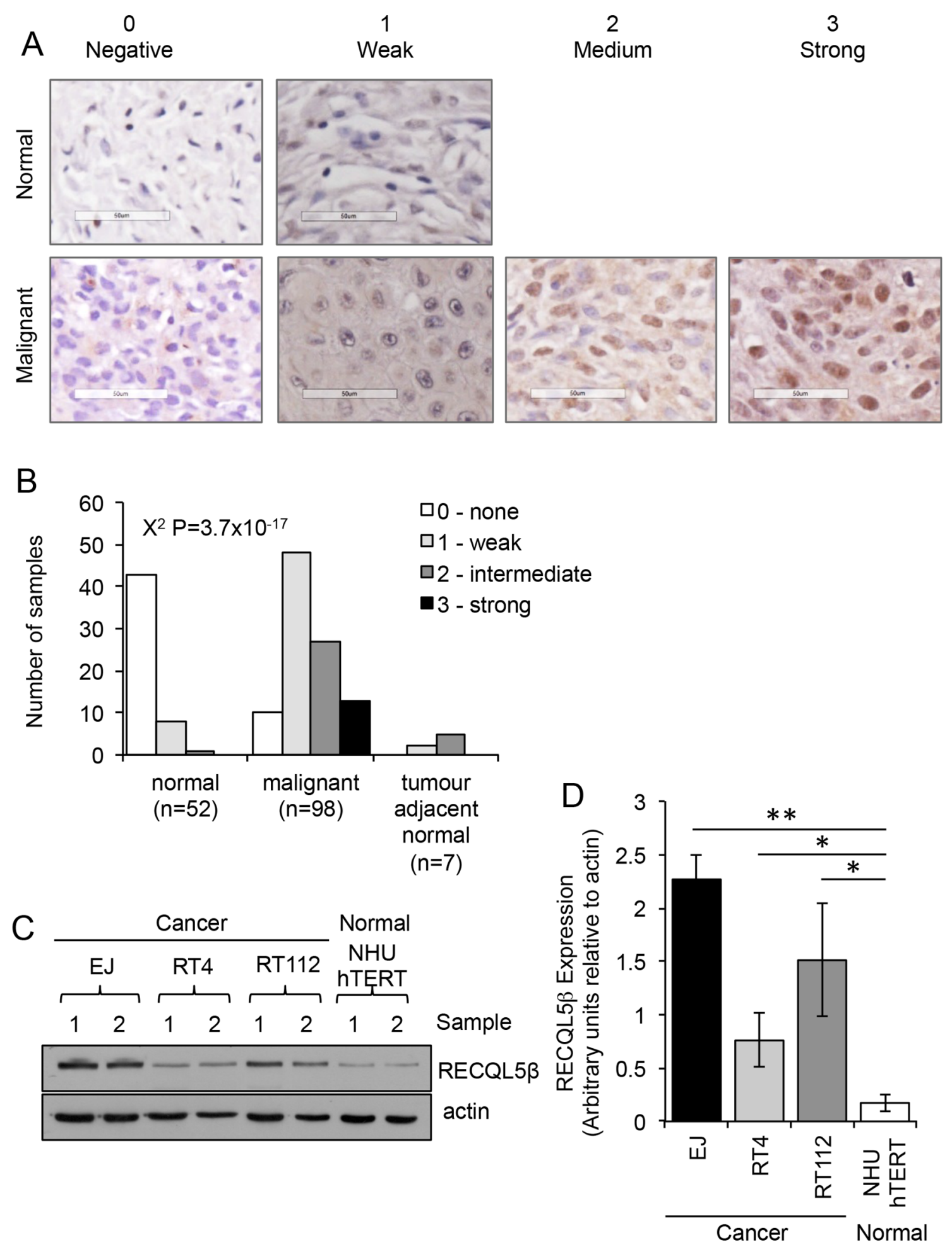

Figure 1: RECQL5 protein expression is increased in UCC. A. Tissue microarray stained for RECQL5 $\beta$ and scored on a scale of 0-3 depending on whether the nuclear staining was negative, weak, medium, or strong respectively. Examples of normal and malignant tissue in each category are shown. None of the normal samples had medium or strong staining. B. Quantification of staining and statistical significance calculated using Contingency Table Pearson Chi-square test. C. Western blot for RECQL5 $\beta$ in normal immortalised bladder (NHU hTERT) and UCC (EJ, RT4, and RT112) cells; 2 successive passages of the cells are shown. D. Quantification of western blots average and standard deviation of 4 biological repeats is shown, $*$ and $* *$ indicate $p<0.05$ and $p<0.01$ respectively using Students t-test. 

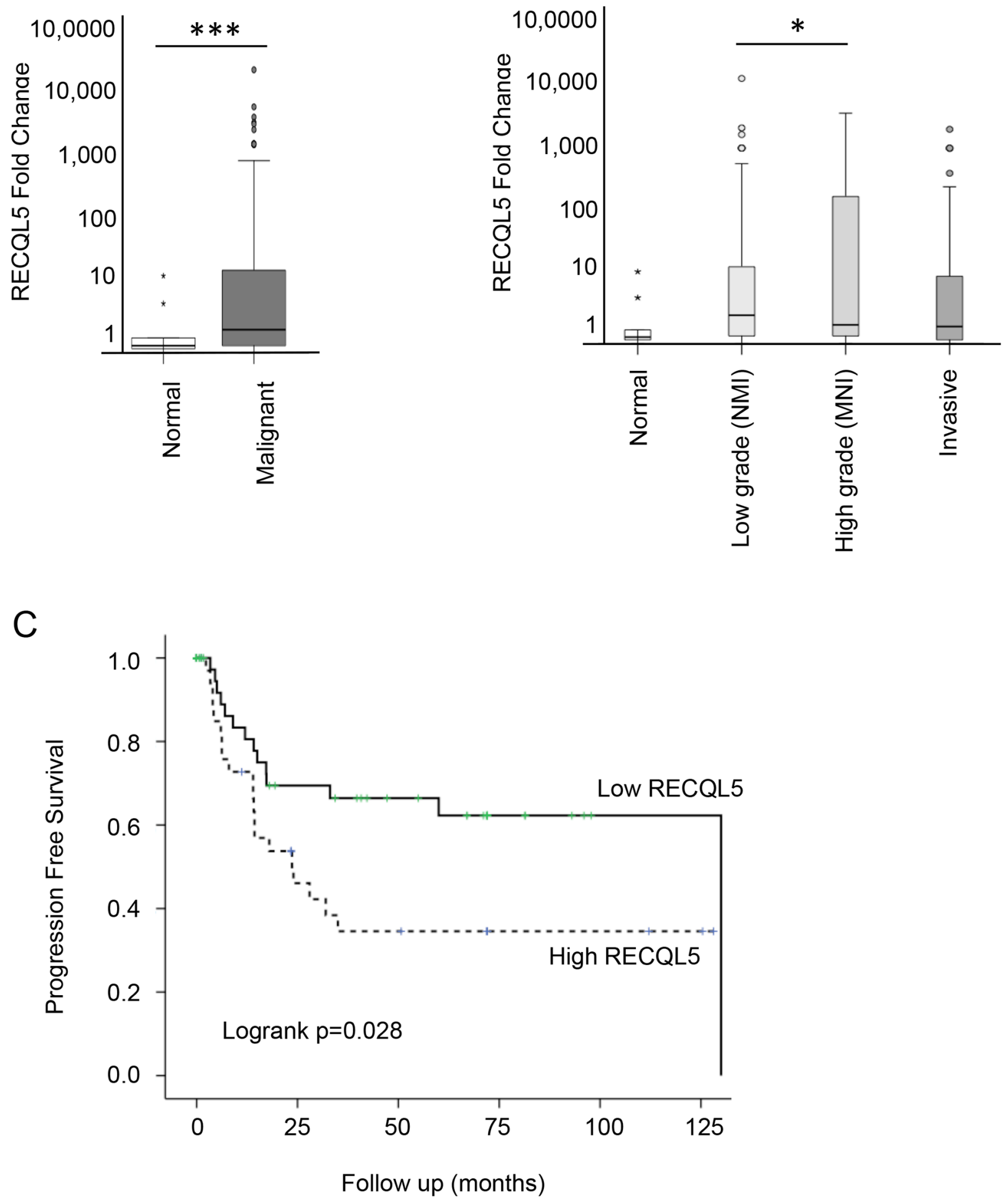

Figure 2: RECQL5 mRNA is increased in UCC and is associated with poor prognosis. Taqman qRT-PCR quantification of mRNA from 197 primary bladder tumour and 20 normal tissue samples using a RECQL5 probe and plotted as fold change [52]. A. Stratified by normal compared to malignant tissue and $\mathbf{B}$. according to tumour grade; * and $* * *$ indicate $p<0.05$ and $\mathrm{p}<0.001$ respectively using Students t-test C. Kaplan Meier curve showing progression free survival based on RECQL5 mRNA expression, $\mathrm{p}$ value calculated as $\log$-rank score. 
To test whether RECQL5 is such a target, UCC and normal bladder cells were depleted of RECQL5 protein using siRNA (Figure 3A). Ninety six hours post transfection the relative survival of bladder cancer cells depleted of either all isoforms of RECQL5 (si1) or specifically RECQL5 $\beta$ (si2) was significantly reduced (Student's t-test, $\mathrm{p}$ value $=5.1 \times 10^{-3}$ and $3.5 \times 10^{-3}$ respectively), while the survival of normal bladder cells was not affected (Figure 3B), suggesting that RECQL5 could be a cancer specific target for therapeutic intervention in UCC. It has been reported that RECQL5 is involved in recovery from DNA crosslinks [31-34] and camptothecin [34, 36] induced DNA damage. Here depletion of RECQL5 (using a pool of RECQL5 si1 and si2) reduced UCC cell survival following treatment with the DNA cross-linking agent $\mathrm{MMC}$ or the topoisomeraise inhibitor camptothecicn compared to treatment with the DNA damaging alone (Figure 3C), suggesting combination therapy could be beneficial.

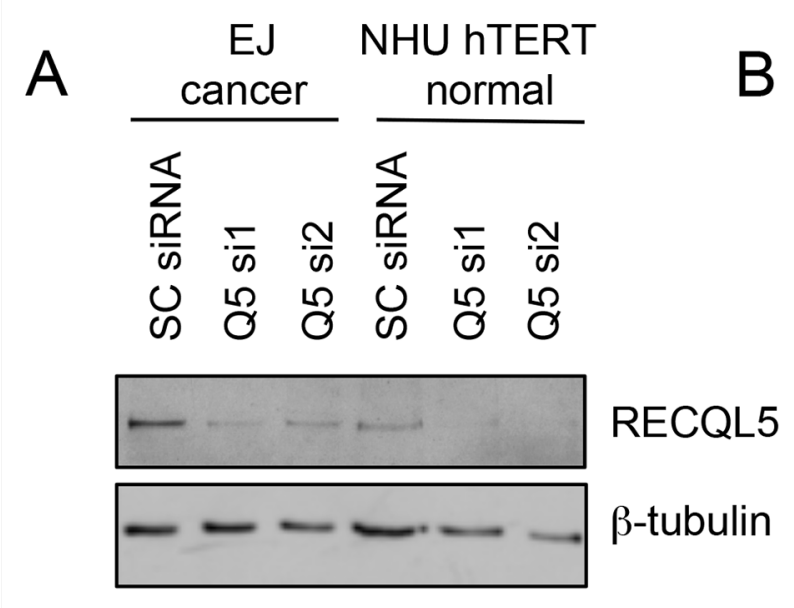

C

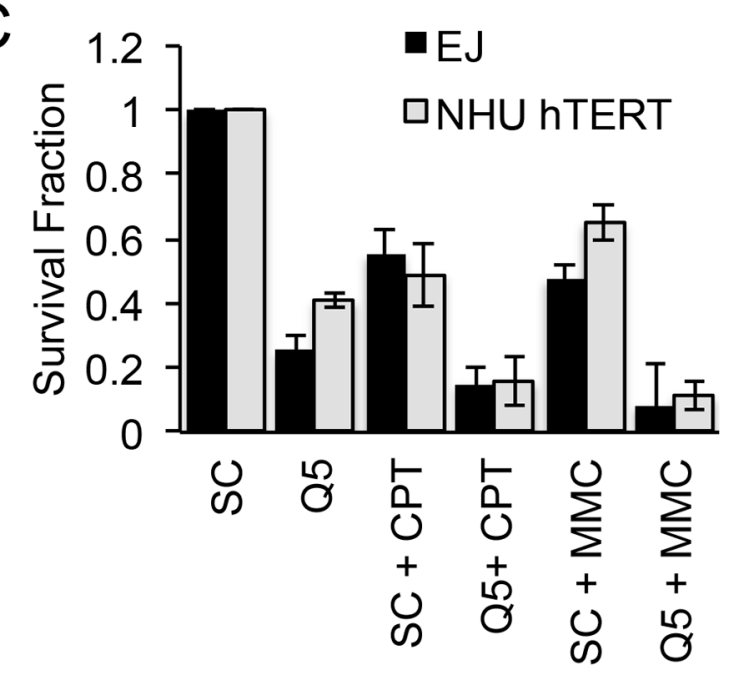

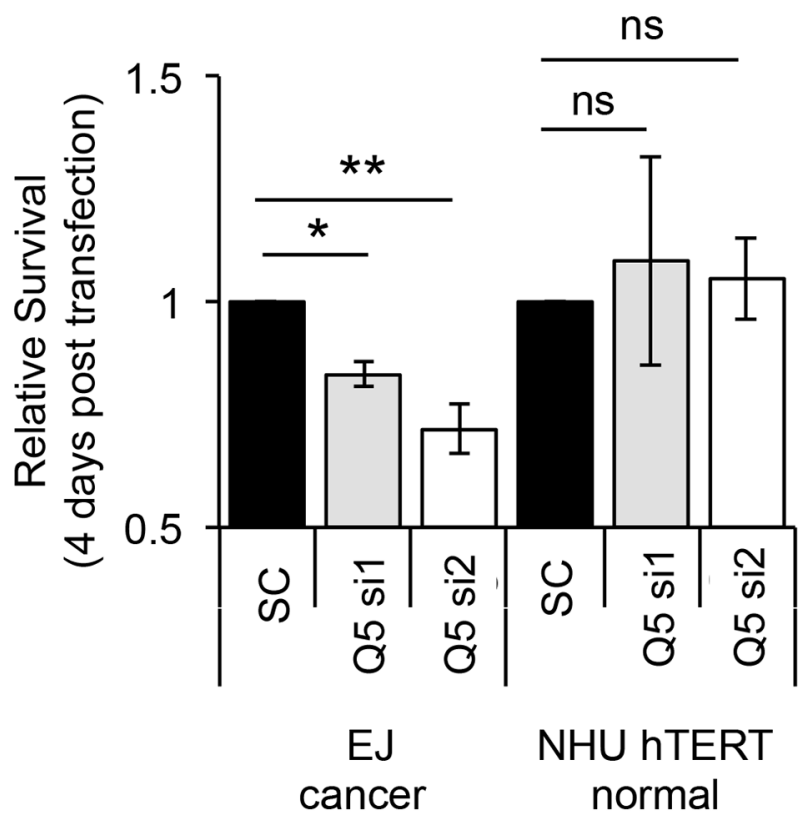

Figure 3: Depletion of RECQL5 reduces survival in bladder cancer cells. A. Western blot for RECQL5 $\beta$ of UCC (EJ) and immortalised normal bladder (NHU hTERT) cells depleted of RECQL5 using siRNA against RECQL5 $\beta$ specifically (Q5 si1) or all 3 isoforms of RECQL5 (Q5 si2) compared to cells treated with non-targeting control (SC) siRNA. B. Survival fraction of corresponding RECQL5 depleted cells $96 \mathrm{~h}$ post siRNA transfection. C. Survival fraction of siRNA treated cells treated with or without $25 \mathrm{nM}$ camptothecin (CPT) or $100 \mathrm{nM}$ mitomycin C (MMC). Average and standard deviation of at least 3 experiments is shown, * and ** indicate $\mathrm{p}<0.05$ and $\mathrm{p}<0.01$ respectively using Students t-test, $\mathrm{ns}=$ not significant. 


\section{Exogenous expression of a helicase dead RECQL5 reduces proliferation and sensitizes to replication stress in UCC cells while expression of RECQL5 increases proliferation in normal bladder cells}

UCC and normal bladder cells were transiently transfected with wildtype (Q5) or helicase dead (Q5KR) RECQL5 $\beta$ (Figure 4D). As UCC cells proliferate faster than normal bladder cells the relative effect of expression of Q5 and Q5KR was compared after 3 cell doublings which corresponded to $48 \mathrm{~h}$ for UCC and $96 \mathrm{~h}$ for normal bladder cells. Proliferation of Q5KR transfected UCC cells (EJ) was significantly decreased compared to Q5 or empty vector (EV) transfected cancer cells (Figure 4A\&4C) (Student's t-test, $\mathrm{p}$ value $=5.1 \times 10^{-4}-\mathrm{Q} 5 \mathrm{KR}$ c.f. EV at $48 \mathrm{~h}$ ). This effect was not seen in normal cells
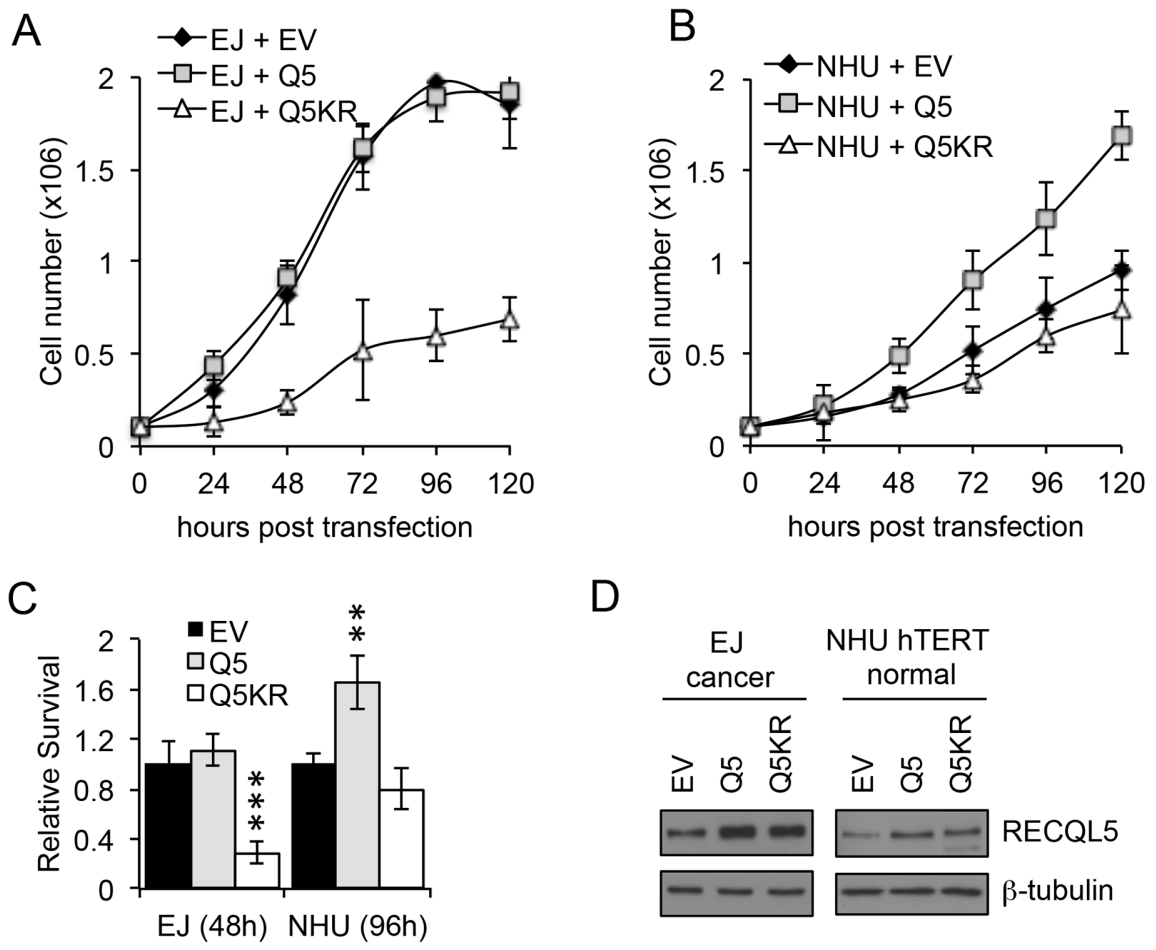

D
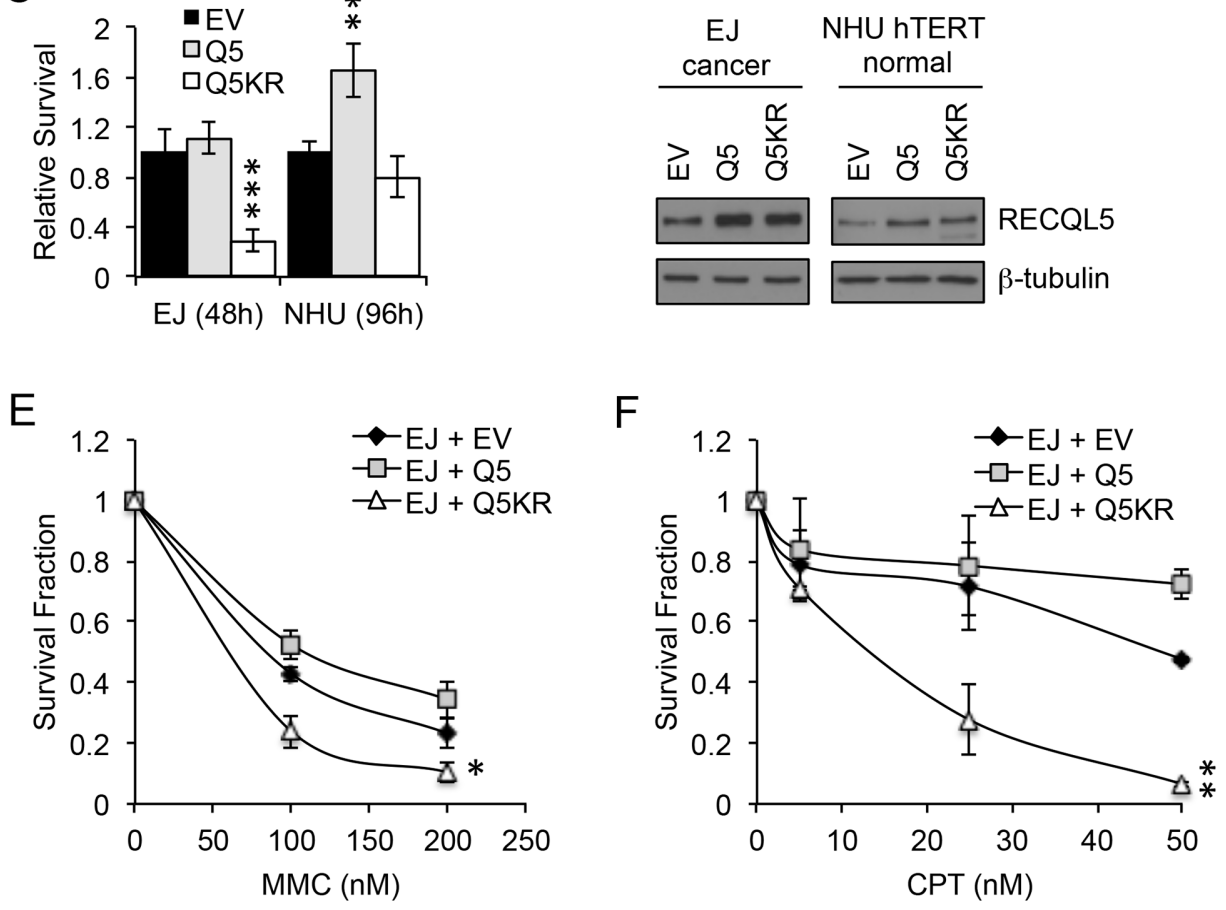

Figure 4: Exogenous expression of RECQL5ß increases proliferation in normal bladder cells and expression of helicase dead RECQL5. A and C. Normal immortalised bladder (NHU hTERT) cells and UCC (EJ) cells transiently transfected with empty vector (MOCK), wildtype RECQL5 $\beta$ (Q5) or helicase dead RECQL5 $\beta$ (Q5KR) and western blotted for RECQL $5 \beta$. B and D. Cell number in each of the transfected conditions after 24, 48, 72, 96 and $120 \mathrm{~h}$. Average and standard deviation of 3 independent repeats is shown. Significance was calculated using a student's t-test, ***indicates $\mathrm{p}<0.001$ comparing MOCK to Q5KR transfected EJ cells at $120 \mathrm{~h}$ posttransfection and **indicates $\mathrm{p}<0.01$ comparing MOCK to Q5 transfected NHU hTERT cells at $120 \mathrm{~h}$. E and F. Clonogenic survival fraction of EJ cells treated as above for $48 \mathrm{~h}$ then replated into mitomycin C (MMC) or camptothecin (CPT). Average and standard deviation of 3 independent repeats is shown. Significance was calculated using a student's t-test, $* *$ indicates $\mathrm{p}<0.01$ and *indicates $\mathrm{p}<0.05$ comparing Q5 to Q5KR transfected EJ cells. 
(NHU) (Figure 4B\&4C). In contrast to the helicase dead Q5 ectopic expression of wildtype Q5 in UCC cells did not alter proliferation compared to EV transfected cells (Figure 4A\&4C), while it's expression in non-tumour NHU hTERT cells significantly increased proliferation compared to $\mathrm{EV}$ or Q5KR transfected cells (Figure $4 \mathrm{~B} \& 4 \mathrm{C}$ ) (Student's t-test, $\mathrm{p}$ value $=4 \times 10^{-3}-\mathrm{Q} 5$ c.f. $\mathrm{EV}$ at $96 \mathrm{~h})$.

UCC cells were also transfected with Q5 or Q5KR, then replated into $\mathrm{MMC}$ or camptothecin for 10 days. Colony survival assays, normalised for effect of ectopic expression Q5/Q5KR alone, showed that in this cell line over expression of Q5KR can sensitize to DNA damaging agents (Figure 4E and 4F) (Student's t-test, $\mathrm{p}$ value $=0.014 \mathrm{MMC}$ and $\mathrm{p}=0.0015$ camptothecicn Q5KR c.f. Q5).

These data again suggest that RECQL5 $\beta$ helicase activity maybe a valid target for specific killing of UCC and for sensitising UCC to conventional chemotheraputics. Further they provide evidence that overexpression of RECQL5 may contribute to increased proliferation and thus cellular transformation in bladder cells.

\section{DISCUSSION}

To date no inherited cancer predisposition syndrome has been associated with RECQL5. However reports of alteration in RECQL5 in sporadic cancer are emerging, these include polymorphisms associated with cancer [19, 22-24], one report that RECQL5 mRNA and protein levels are reduced in colorectal cancer (CRC) [42] and a recent report by our lab showing high levels of RECQL5 are associated with aggressive phenotypes and poor survival outcomes in breast cancer [25]. In contrast to CRC, here RECQL5 mRNA and nuclear RECQL5 $\beta$ protein were increased in UCC when compared to normal tissue. This is slightly unexpected given that RECQL5 deficient mice are cancer-prone and suggests that, like several other members of the RECQ helicase family [25, 43], increased expression of RECQL5 can also be associated with cancer. Normal bladder cells could be induced to proliferate by exogenous expression of wildtype but not helicase dead RECQL5 $\beta$ demonstrating a potential functional role of increased RECQL5 $\beta$ expression in cellular transformation. Previously overexpression of RECQL5 $\beta$ has been shown to allow cells to overcome replication stress [35] and it is possible that an ability to overcome replication stress gives cells a selective advantage during tumourigenesis. However the consequence of doing so maybe genomic instability, as overexpression of RECQL5 $\beta$ also reduces replication stress induced checkpoint activation and homologous recombination [35]. Interesting in breast cancer we previously showed that high RECQL5 protein level needed to be associated with low RAD51 protein expression to infer poor survival, suggesting a functional relationship between RECQL5 and RAD51 pathways influences breast cancer tumour progression or response to therapy [25].

Consistent with findings in breast cancer [25] increased RECQL5 mRNA was associated with poor prognosis in bladder cancer, suggesting value as a prognostic marker, perhaps with particular value in identifying high-grade tumours which are likely to progress to more serious disease. In addition RECQL5 $\beta$ protein expression tended to have stronger staining in higher-grade metastatic disease.

Exogenous expression of RECQL5 $\beta$ in normal bladder cells increased proliferation, while expression of a helicase dead mutant did not significantly alter growth. In contrast no change in growth was seen when wildtype The The potential of RECQL5 as a therapeutic target has been discussed previously in other cancers $[25,34,35,44]$. RECQL5 $\beta$ levels were increased in bladder cancer cells, while overexpression of a helicase dead RECQL5 protein or siRNA mediated depletion of RECQL5 resulted in reduced cell survival in UCC cells. In addition depletion of RECQL5 or expression of helicase dead RECQL5 increased cell death in MMC and camptothecin treated UCC cells. Taken together these data demonstrate the potential of RECQL5 as a therapeutic target in UCC. Given that several other RECQ helicases have recently been successfully and specifically targeted by small molecule inhibitors $[22,45]$, it maybe be possible and timely to develop RECQL5 inhibitors for use as chemotherapeutics either as monotherapies or combined with conventional DNA damaging agents.

In summary we have shown that increased expression of RECQL5 protein occurs and is likely to contribute to tumourigenesis in UCC and that the pharmacological targeting of the helicase activity of RECQL5 is a strong target for future small molecule inhibitor development.

\section{MATERIALS AND METHODS}

\section{Human UCC tissue microarrays}

UCC tissue microarrays (BL1002, BL802a, and BNC12011) were purchased from US Biomax, Inc. TMAs contained $1 \mathrm{~mm}$ diameter and $5 \mu \mathrm{M}$ thickness cores from formalin-fixed paraffin-embedded (FFPE) samples, some samples were sparse and could not be analysed. Samples that were analysed are shown in Supplementary Table S1, these included 90 urothelial carcinoma, 4 squamous cell carcinoma, 4 adenocarcinoma, 7 adjacent normal bladder tissues and 52 normal tissues. Further data for cases can be found at http://www.biomax.us/tissue-arrays/Bladder/BL1002, http://www.biomax.us/tissue-arrays/Bladder/BL802a, http://www.biomax.us/tissue-arrays/Bladder/BNC12011 and Supplementary Table S1). 


\section{Patients and tumours}

We selected new freshly frozen primary tumours treated at the Royal Hallamshire Hospital Sheffield, UK. TUCC were classified using the 2004 WHO/ISUP criteria and treated according to standard care [46, 47]. For comparison we obtained disease free urothelium from patients undergoing radical prostatectomy for prostate cancer. All tissues were confirmed using H\&E sections and micro dissected to obtain cell populations with $>80 \%$ purity. Following resection, all patients were followed for progression (defined as a second bladder tumour of increased stage or until metastases developed). Patient demographics are summarized in Supplementary Table S1 of supporting information. Collection of samples was performed after obtaining informed consent and within an ethics committee approved collection (South Yorks Ethics committee 10/H1310/73).

\section{Cell lines}

UCC cell lines EJ [48], RT112 [48] and RT4 [49] were grown in DMEM with $10 \%$ fetal calf serum. Immortalised normal human urothelium cells [50] were grown in Keratinocyte Serum Free Media (KSFM) supplemented with epidermal growth factor (EGF) (5 ng/ $\mathrm{ml})$ and bovine pituitary extract (BPE) $(50 \mathrm{ng} / \mathrm{ml})(\mathrm{Gibco})$ with $30 \mathrm{ng} / \mathrm{ml}$ of cholera toxin (Sigma-Aldrich Company Ltd, Poole, UK).

\section{RECQL5 helicase expression using IHC}

TMAs were deparaffinised and rehydrated in distilled water. IHC, antigen retrieval was performed using heat-induced epitope retrieval buffer (Sodium Citrate Buffer, $10 \mathrm{mM}$ Sodium Citrate, $0.05 \%$ Tween 20, $\mathrm{pH} 6$ ). Endogenous peroxidase activity was blocked using $3 \% \mathrm{H}_{2} \mathrm{O}_{2}$. Anti-RECQL5 rabbit polyclonal antibody (Sigma-Aldrich; HPA029971) was diluted 1:150 in 2\% goat serum, $2 \%$ casein in PBS. TMAs were incubated with primary antibody overnight at $4^{\circ} \mathrm{C}$. 3,3-Diaminobenzidine substrate was used to visualize RECQ-positive cells. TMAs were counterstained with hematoxylin. Nuclear staining was scored using an intensity score ranging from 0 to $3(0=$ negative, $1=$ weak intensity nuclear staining or staining $<30 \%$ nuclei, $2=$ medium intensity staining or staining $<60 \%$ nuclei, $3=$ strong intensity nuclear staining in $>60 \%$ nuclei.

For optimization of IHC EJ cells depleted of RECQL5 using pooled siRNA as below were fixed in $4 \%$ paraformaldehyde/PBS overnight, before PFA was replaced first with $70 \%$ ethanol then with $2 \%$ agarose$4 \%$ formaldehyde and being embedded in wax and sectioned (Supplementary Figure S1A), an IgG control was also included for these pellets. These demonstrate that when RECQL5 is depleted the signal is reduced indicating specificity of primary antibody to the antigen
RECQL5. Second an IgG control was used on a test TMA in parallel to each experiment (Supplementary Figure S1B), demonstrating that on each occasion the staining is dependent on the primary antibody rather than a reaction of the secondary antibody. There is also there is also an internal negative control of fibroblast nuclei within the bladder stroma in the arrays, if staining.

Slides were imaged using an Aperio Slide Scanner. Scoring was performed by a trained pathologist. Significance was calculated using Stata Data Analysis and Statistical Software, Version 12.

\section{Quantitative real-time PCR}

RNA from the UCC and normal urothelial cell lines (NHU, RT4, RT112 and EJ) and primary UCC and normal samples was extracted using the RNeasy Mini Kit (Qiagen, Manchester, UK). Approximately $1 \times 10^{6}$ cells were used and manufacturer's instructions were followed to isolate $5-35 \mu \mathrm{g}$ of total RNA. cDNA was generated from RNA using the Applied Biosciences High Capacity cDNA Reverse Transcription Kit. RT-PCR was performed using TaqMan probe and primers (Applied Biosystems, Grand Island, NY) for RECQL5 $\beta$ (Hs00696986_g1) and RECQL5 non isotype specific (Hs00188633_m1), Heat shock protein $90 \mathrm{kDa}$ alpha (cytosolic), class B member 1 (HSP90AB1) (Hs03043878_g1), Testis enhanced gene transcript protein (TEGT) (Hs01012085_m1) and Mitochondrial ATP synthase $\mathrm{H}+$ transporting F1 complex beta subunit (ATP5B) (Hs00969573_mH) with TaqMan Universal PCR Mix (Applied Biosystems) as recommended by the manufacturer. The dissociation curve was then calculated. $\Delta \mathrm{CT}$ values were calculated normalisation to the median of 4 housekeeping genes TEGT, ATP58, HSP90AB and PCNA chosen from previous reports in bladder cancer [51]. Fold change was calculated using DDCt methods [52]. Outcomes with respect to time were plotted using the Kaplan-Meier method and compared using a Log rank test within SPSS (Vsn. 19.0 SPSS Inc.).

\section{Western blotting}

Cells were lysed in lysis buffer (50 mM HEPES, $150 \mathrm{mM} \mathrm{NaCl}, 1 \mathrm{mM}$ EDTA, 1 mM EGTA, 10\% Glycerol, $1 \%$ Triton X100, Complete Protease inhibitor complex (Roche, Welwyn Garden City, UK), Phosphatase inhibitor complex 1 and Phosphatase inhibitor complex 2 (SigmaAldrich). $50 \mu \mathrm{g}$ total protein was resolved on an SDSPAGE gel and transferred to Hybond ECL membrane (GE Healthcare Life Sciences, Little Chalfont, UK). This membrane was immunoblotted with rabbit anti-RECQL5 (AB91422, 1:2000, Abcam, Cambridge, UK), rabbit anti-eLF2 $\alpha$ (9722, Cell signalling technology, Danvers, MA), rabbit anti-eLF2 $\alpha$-pS51 (9721, Cell signalling technology) and rabbit anti- $\beta$-ACTIN (A2228, 1:2000, 
Sigma-Aldrich) or mouse anti- $\beta$-tubulin (T8328, 1:1000, Sigma-Aldrich), antibodies in 5\% milk overnight. After addition of the appropriate HRP conjugated secondary antibody and further washes, immunoreactive protein was visualised using ECL reagents (GE Healthcare Life Sciences) following manufacturers' instructions. Intensity was analysed using imageJ image processing software.

\section{Plasmids and siRNA}

pcDNA 3.1 plasmids containing human RECQL5 $\beta$ cDNA (Q5) and RECQL5KR (RecQL5 $\beta$ cDNA sequence with the helicase domain disrupted by a K58R point mutation - Q5KR)) were a generous gift from Dr. Pavel Janscak (Institute of Molecular Cancer Research, University of Zurich)

Q5 sil was a pool of two predesigned siGenome siRNA (RECQL5-01 and RECQL5-03, Thermo Scientific, Winsford, UK) designed to target all 3 isoforms of RECQL5, Q5 si2 was a pool of custom oligos (UGAAGAAGGUGGCCGAUAU) and (CUGCAAAUGUUGUGGUCAA) designed only to target RECQL5 $\beta$.

\section{Proliferation assays following overexpression of RECQL5}

$1 \times 10^{5}$ cells were plated 24 hours prior to transfection with $2.5 \mu \mathrm{g}$ of plasmid DNA expressing wildtype RECQL5 $\beta$ (Q5) or helicase dead RECQL5 $\beta$ (Q5KR) [35] using Lipofectamine 2000 (Invitrogen, Grand Island, NY). At various times post transfection cells were trypsinised from replica plates, stained with trypan blue and live cells counted. On each occasion 8 counts of each condition were taken and an average calculated. The experiment was repeated on 3 independent occasions and average and standard deviations calculated.

\section{Survival assays following siRNA mediated depletion of RECQL5}

$20 \mu \mathrm{M}$ siRNA against RECQL5/RECQL5 $\beta$ was reverse transfected into $1 \times 10^{5}$ cells using lipofectamine RNAiMAX. Cells were left 96 hours before counting as above. Relative survival compared to cells transfected with a scrambled control was calculated. The experiment was repeated on 3 independent occasions and average and standard deviations calculated.

\section{Survival in the presence of MMC and camptothecin}

For analysis of sensitivity to DNA damaging agents, cells were treated as above for $48 \mathrm{~h}$ prior to replating into $90 \mathrm{~mm}$ dishes in presence of increasing doses of MMC and camptothecin and then left 10 days for colonies to form before staining with $4 \%$ methylene blue in $70 \%$ methanol and counting. The experiment was repeated on 2 independent occasions and average and standard deviations calculated.

\section{ACKNOWLEDGMENTS}

The authors wish to thank Prof. Meuth and Dr $\mathrm{S}$. Collis for their support and critical reading of this manuscript.

\section{CONFLICTS OF INTEREST}

The authors declare no competing conflicts of interest.

\section{GRANT SUPPORT}

The work was supported by a project grant from Yorkshire Cancer Research (Grant number S305PA). HEB was supported by an RCUK research fellowship.

\section{REFERENCES}

1. Chavan S, Bray F, Lortet-Tieulent J, Goodman M, Jemal A. International variations in bladder cancer incidence and mortality. Eur Urol. 2014; 66:59-73. doi: 10.1016/j. eururo.2013.10.001.

2. Svatek RS, Hollenbeck BK, Holmäng S, Lee R, Kim SP, Stenzl A, Lotan Y. The economics of bladder cancer: costs and considerations of caring for this disease. Eur Urol. 2014; 66:253-62. doi: 10.1016/j.eururo.2014.01.006.

3. Godon C, Cordelières FP, Biard D, Giocanti N, MégninChanet F, Hall J, Favaudon V. PARP inhibition versus PARP-1 silencing: different outcomes in terms of single-strand break repair and radiation susceptibility. Nucleic Acids Res. 2008; 36:4454-64. doi: 10.1093/nar/gkn403.

4. Godon C, Cordelieres FP, Biard DS, Megnin-Chanet F, Hall J, Favaudon V. PARP inhibition vs. PARP-1 silencing: different outcomes in terms of single-strand break repair. Eur J Cancer, Suppl. 2008; 6:55. doi: 10.1016/S1359-6349(08)71386-7.

5. Schlicker A, Peschke P, Bürkle A, Hahn EW, Kim JH. 4-Amino-1,8-naphthalimide: a novel inhibitor of poly(ADPribose) polymerase and radiation sensitizer. Int J Radiat Biol. 1999; 75:91-100. doi: 10.1080/095530099140843.

6. Damrauer JS, Hoadley KA, Chism DD, Fan C, Tiganelli CJ, Wobker SE, Yeh JJ, Milowsky MI, Iyer G, Parker JS, Kim WY. Intrinsic subtypes of high-grade bladder cancer reflect the hallmarks of breast cancer biology. Proc Natl Acad Sci USA. 2014; 111:3110-15. doi: 10.1073/pnas.1318376111.

7. Choi W, Porten S, Kim S, Willis D, Plimack ER, HoffmanCensits J, Roth B, Cheng T, Tran M, Lee IL, Melquist J, Bondaruk J, Majewski T, et al. Identification of distinct basal and luminal subtypes of muscle-invasive bladder cancer with different sensitivities to frontline chemotherapy. Cancer Cell. 2014; 25:152-65. doi: 10.1016/j.ccr.2014.01.009. 
8. Trucco C, Oliver FJ, de Murcia G, Ménissier-de Murcia J. DNA repair defect in poly(ADP-ribose) polymerasedeficient cell lines. Nucleic Acids Res. 1998; 26:2644-49. doi: 10.1093/nar/26.11.2644.

9. Chalmers A, Johnston P, Woodcock M, Joiner M, Marples B. PARP-1, PARP-2, and the cellular response to low doses of ionizing radiation. Int J Radiat Oncol Biol Phys. 2004; 58:410-19. doi: 10.1016/j.ijrobp.2003.09.053.

10. de Murcia JM, Niedergang C, Trucco C, Ricoul M, Dutrillaux B, Mark M, Oliver FJ, Masson M, Dierich A, LeMeur M, Walztinger C, Chambon P, de Murcia G. Requirement of poly(ADP-ribose) polymerase in recovery from DNA damage in mice and in cells. Proc Natl Acad Sci USA. 1997; 94:730307. doi: 10.1073/pnas.94.14.7303.

11. Bartkova J, Horejsí Z, Koed K, Krämer A, Tort F, Zieger K, Guldberg P, Sehested M, Nesland JM, Lukas C, Ørntoft T, Lukas J, Bartek J. DNA damage response as a candidate anticancer barrier in early human tumorigenesis. Nature. 2005; 434:864-70. doi: 10.1038/nature03482.

12. Wang L, Mason KA, Ang KK, Buchholz T, Valdecanas D, Mathur A, Buser-Doepner C, Toniatti C, Milas L. MK-4827, a PARP-1/-2 inhibitor, strongly enhances response of human lung and breast cancer xenografts to radiation. Invest New Drugs. 2012; 30:2113-20. doi: 10.1007/s10637-011-9770-x.

13. Dietlein F, Thelen L, Reinhardt HC. Cancer-specific defects in DNA repair pathways as targets for personalized therapeutic approaches. Trends Genet. 2014; 30:326-39. doi: 10.1016/j. tig.2014.06.003.

14. Bryant HE, Schultz N, Thomas HD, Parker KM, Flower D, Lopez E, Kyle S, Meuth M, Curtin NJ, Helleday T. Specific killing of BRCA2-deficient tumours with inhibitors of poly(ADP-ribose) polymerase. Nature. 2005; 434:913-17. doi: 10.1038/nature03443.

15. Farmer H, McCabe N, Lord CJ, Tutt AN, Johnson DA, Richardson TB, Santarosa M, Dillon KJ, Hickson I, Knights C, Martin NM, Jackson SP, Smith GC, Ashworth A. Targeting the DNA repair defect in BRCA mutant cells as a therapeutic strategy. Nature. 2005; 434:917-21. doi: 10.1038/nature03445.

16. Ali M, Kamjoo M, Thomas HD, Kyle S, Pavlovska I, Babur M, Telfer BA, Curtin NJ, Williams KJ. The clinically active PARP inhibitor AG014699 ameliorates cardiotoxicity but does not enhance the efficacy of doxorubicin, despite improving tumor perfusion and radiation response in mice. Mol Cancer Ther. 2011; 10:2320-29. doi: 10.1158/1535-7163.MCT-11-0356.

17. Furuichi Y. Premature aging and predisposition to cancers caused by mutations in RecQ family helicases. Ann N Y Acad Sci. 2001; 928:121-31. doi: 10.1111/j.17496632.2001.tb05642.x.

18. Donawho CK, Luo Y, Luo Y, Penning TD, Bauch JL, Bouska JJ, Bontcheva-Diaz VD, Cox BF, DeWeese TL, Dillehay LE, Ferguson DC, Ghoreishi-Haack NS, Grimm DR, et al. ABT-888, an orally active poly(ADP-ribose) polymerase inhibitor that potentiates DNA-damaging agents in preclinical tumor models. Clin Cancer Res. 2007; 13:2728-37. doi: 10.1158/1078-0432.CCR-06-3039.
19. Zhi LQ, Ma W, Zhang H, Zeng SX, Chen B. Association of RECQL5 gene polymorphisms and osteosarcoma in a Chinese Han population. Tumour Biol. 2014; 35:3255-59. doi: 10.1007/s13277-013-1425-4.

20. Calabrese CR, Almassy R, Barton S, Batey MA, Calvert AH, Canan-Koch S, Durkacz BW, Hostomsky Z, Kumpf RA, Kyle S, Li J, Maegley K, Newell DR, et al. Anticancer chemosensitization and radiosensitization by the novel poly(ADP-ribose) polymerase-1 inhibitor AG14361. J Natl Cancer Inst. 2004; 96:56-67. doi: 10.1093/jnci/djh005.

21. Venere M, Hamerlik P, Wu Q, Rasmussen RD, Song LA, Vasanji A, Tenley N, Flavahan WA, Hjelmeland AB, Bartek J, Rich JN. Therapeutic targeting of constitutive PARP activation compromises stem cell phenotype and survival of glioblastoma-initiating cells. Cell Death Differ. 2014; $21: 258$ 69. doi: 10.1038/cdd.2013.136.

22. Dong YZ, Huang YX, Lu T. Single nucleotide polymorphism in the RECQL5 gene increased osteosarcoma susceptibility in a Chinese Han population. Genet Mol Res. 2015; 14:1899902. doi: 10.4238/2015.March.13.18.

23. He YJ, Qiao ZY, Gao B, Zhang XH, Wen YY. Association between RECQL5 genetic polymorphisms and susceptibility to breast cancer. Tumour Biol. 2014; 35:12201-04. doi: 10.1007/s13277-014-2528-2.

24. Qi Y, Zhou X. Haplotype analysis of RECQL5 gene and laryngeal cancer. Tumour Biol. 2014; 35:2669-73. doi: 10.1007/s13277-013-1351-5.

25. Arora A, Abdel-Fatah TM, Agarwal D, Doherty R, Croteau DL, Moseley PM, Hameed K, Green A, Aleskandarany MA, Rakha EA, Patterson K, Ball G, Chan SY, et al. Clinicopathological and prognostic significance of RECQL5 helicase expression in breast cancers. Carcinogenesis. 2016; 37:63-71. doi: 10.1093/carcin/bgv163.

26. Hu Y, Lu X, Barnes E, Yan M, Lou H, Luo G. Recql5 and Blm RecQ DNA helicases have nonredundant roles in suppressing crossovers. Mol Cell Biol. 2005; 25:3431-42. doi: 10.1128/ MCB.25.9.3431-3442.2005.

27. Hu Y, Raynard S, Sehorn MG, Lu X, Bussen W, Zheng L, Stark JM, Barnes EL, Chi P, Janscak P, Jasin M, Vogel $\mathrm{H}$, Sung $\mathrm{P}$, Luo G. RECQL5/Recq15 helicase regulates homologous recombination and suppresses tumor formation via disruption of Rad51 presynaptic filaments. Genes Dev. 2007; 21:3073-84. doi: 10.1101/gad.1609107.

28. Li M, Xu X, Liu Y. The SET2-RPB1 interaction domain of human RECQ5 is important for transcription-associated genome stability. Mol Cell Biol. 2011; 31:2090-99. doi: 10.1128/MCB.01137-10.

29. Ramamoorthy M, Tadokoro T, Rybanska I, Ghosh AK, Wersto R, May A, Kulikowicz T, Sykora P, Croteau DL, Bohr VA. RECQL5 cooperates with Topoisomerase II alpha in DNA decatenation and cell cycle progression. Nucleic Acids Res. 2012; 40:1621-35. doi: 10.1093/nar/gkr844.

30. Tadokoro T, Ramamoorthy M, Popuri V, May A, Tian J, Sykora P, Rybanska I, Wilson DM 3rd, Croteau DL, Bohr VA. 
Human RECQL5 participates in the removal of endogenous DNA damage. Mol Biol Cell. 2012; 23:4273-85. doi: 10.1091/mbc.E12-02-0110.

31. Ramamoorthy M, May A, Tadokoro T, Popuri V, Seidman MM, Croteau DL, Bohr VA. The RecQ helicase RECQL5 participates in psoralen-induced interstrand cross-link repair. Carcinogenesis. 2013; 34:2218-30. doi: 10.1093/carcin/bgt183.

32. Hosono $\mathrm{Y}$, Abe T, Ishiai M, Islam MN, Arakawa H, Wang W, Takeda S, Ishii Y, Takata M, Seki M, Enomoto T. Tumor suppressor RecQL5 controls recombination induced by DNA crosslinking agents. Biochim Biophys Acta. 2014; 1843:1002-12. doi: 10.1016/j.bbamcr.2014.01.005.

33. Zheng L, Kanagaraj R, Mihaljevic B, Schwendener S, Sartori AA, Gerrits B, Shevelev I, Janscak P. MRE11 complex links RECQ5 helicase to sites of DNA damage. Nucleic Acids Res. 2009; 37:2645-57. doi: 10.1093/nar/gkp147.

34. Kim TM, Son MY, Dodds S, Hu L, Luo G, Hasty P. RECQL5 and BLM exhibit divergent functions in cells defective for the Fanconi anemia pathway. Nucleic Acids Res. 2015; 43:893903. doi: 10.1093/nar/gku1334.

35. Blundred R, Myers K, Helleday T, Goldman AS, Bryant HE. Human RECQL5 overcomes thymidine-induced replication stress. DNA Repair (Amst). 2010; 9:964-75. doi: 10.1016/j. dnarep.2010.06.009.

36. Hu Y, Lu X, Zhou G, Barnes EL, Luo G. Recql5 plays an important role in DNA replication and cell survival after camptothecin treatment. Mol Biol Cell. 2009; 20:114-23. doi: 10.1091/mbc.E08-06-0565.

37. Aygün O, Svejstrup JQ. RECQL5 helicase: connections to DNA recombination and RNA polymerase II transcription. DNA Repair (Amst). 2010; 9:345-53. doi: 10.1016/j. dnarep.2009.12.008.

38. Aygün $\mathrm{O}, \mathrm{Xu} \mathrm{X}$, Liu Y, Takahashi H, Kong SE, Conaway RC, Conaway JW, Svejstrup JQ. Direct inhibition of RNA polymerase II transcription by RECQL5. J Biol Chem. 2009; 284:23197-203. doi: 10.1074/jbc.M109.015750.

39. Saponaro M, Kantidakis T, Mitter R, Kelly GP, Heron M, Williams H, Söding J, Stewart A, Svejstrup JQ. RECQL5 controls transcript elongation and suppresses genome instability associated with transcription stress. Cell. 2014; 157:1037-49. doi: 10.1016/j.cell.2014.03.048.

40. Kanagaraj R, Huehn D, MacKellar A, Menigatti M, Zheng L, Urban V, Shevelev I, Greenleaf AL, Janscak P. RECQ5 helicase associates with the C-terminal repeat domain of RNA polymerase II during productive elongation phase of transcription. Nucleic Acids Res. 2010; 38:8131-40. doi: 10.1093/nar/gkq697.

41. Shimamoto A, Nishikawa K, Kitao S, Furuichi Y. Human RecQ5beta, a large isomer of RecQ5 DNA helicase, localizes in the nucleoplasm and interacts with topoisomerases 3alpha and 3beta. Nucleic Acids Res. 2000; 28:1647-55. doi: 10.1093/nar/28.7.1647.

42. Lao VV, Welcsh P, Luo Y, Carter KT, Dzieciatkowski S, Dintzis S, Meza J, Sarvetnick NE, Monnat RJ Jr, Loeb LA,
Grady WM. Altered RECQ Helicase Expression in Sporadic Primary Colorectal Cancers. Transl Oncol. 2013; 6:458-69. doi: 10.1593/tlo.13238.

43. Sharma S. An appraisal of RECQ1 expression in cancer progression. Front Genet. 2014; 5:426. doi: 10.3389/ fgene.2014.00426.

44. Wang X, Lu X, Zhou G, Lou H, Luo G. RECQL5 is an important determinant for camptothecin tolerance in human colorectal cancer cells. Biosci Rep. 2011; 31:363-69. doi: 10.1042/BSR20100108.

45. Liao WQ, Qi YL, Wang L, Dong XM, Xu T, Ding CD, Liu R, Liang WC, Lu LT, Li H, Li WF, Luo GB, Lu XC. Recq15 protects against lipopolysaccharide/D-galactosamine-induced liver injury in mice. World J Gastroenterol. 2015; 21:1037584. doi: 10.3748/wjg.v21.i36.10375.

46. Thomas F, Noon AP, Rubin N, Goepel JR, Catto JW. Comparative outcomes of primary, recurrent, and progressive high-risk non-muscle-invasive bladder cancer. Eur Urol. 2013; 63:145-54. doi: 10.1016/j.eururo.2012.08.064.

47. Sylvester RJ, Oosterlinck W, Holmang S, Sydes MR, Birtle A, Gudjonsson S, De Nunzio C, Okamura K, Kaasinen E, Solsona E, Ali-El-Dein B, Tatar CA, Inman BA, et al. Systematic Review and Individual Patient Data Metaanalysis of Randomized Trials Comparing a Single Immediate Instillation of Chemotherapy After Transurethral Resection with Transurethral Resection Alone in Patients with Stage pTa-pT1 Urothelial Carcinoma of the Bladder: Which Patients Benefit from the Instillation? Eur Urol. 2016; 69:231-44. doi: 10.1016/j.eururo.2015.05.050.

48. Ariumi Y, Masutani M, Copeland TD, Mimori T, Sugimura T, Shimotohno K, Ueda K, Hatanaka M, Noda M. Suppression of the poly(ADP-ribose) polymerase activity by DNAdependent protein kinase in vitro. Oncogene. 1999; 18:461625. doi: 10.1038/sj.onc.1202823.

49. Li B, Navarro S, Kasahara N, Comai L. Identification and biochemical characterization of a Werner's syndrome protein complex with Ku70/80 and poly(ADP-ribose) polymerase-1. J Biol Chem. 2004; 279:13659-67. doi: 10.1074/jbc. M311606200.

50. Paddock MN, Bauman AT, Higdon R, Kolker E, Takeda S, Scharenberg AM. Competition between PARP-1 and Ku70 control the decision between high-fidelity and mutagenic DNA repair. DNA Repair (Amst). 2011; 10:338-43. doi: 10.1016/j.dnarep.2010.12.005.

51. Andersen CL, Jensen JL, Ørntoft TF. Normalization of realtime quantitative reverse transcription-PCR data: a modelbased variance estimation approach to identify genes suited for normalization, applied to bladder and colon cancer data sets. Cancer Res. 2004; 64:5245-50. doi: 10.1158/0008-5472. CAN-04-0496.

52. Schmittgen TD, Lee EJ, Jiang J, Sarkar A, Yang L, Elton TS, Chen C. Real-time PCR quantification of precursor and mature microRNA. Methods. 2008; 44:31-38. doi: 10.1016/j. ymeth.2007.09.006. 